falls under the present system of dispensing and vending poisonous medicines; and it will be on the present occasion, unless the attention which has been attracted to it by your leader in last week's LANCET shall induce those whom it may concern to adopt some efficient scheme of precautions and saferuards.

The Act to Amend the Law relating to the Unlawful Admi. nistering of Poisons, passed by the Government in February last, supplies a great defect in our criminal law, and will no donbt do much to prevent the perpetration of such offences as that which was the immediate cause of its enactment; but it does nothing to affect the indiscriminate sale of poisons, and makes no attempt to provile against what are called "accidental poisonings." Former attempts at legislation on this matter have failed, because of the impracticability of the measures which have been proposed. The authors of such measures have constructed schedules of poisons from which more dangerous substances have been omitted than any included; and they have attempted to place restrictions on the sale of articles in such constant demand amongst artizans of all classes, as to make it utterly impossible to carry the law into effect. With the sale of those poisons in constant use amongst artists, mechanics, and others, we believe it to be as impossible to inter fere as with the sale of lucifer matches, which are now the favourite instruments of suicide and murder in France and Germany. But the "accidental poisonings"-those cases in which a druggist sells a customer laudanum for tincture of rhubarb or black-draught, or in which a relative or nurse ad ministers to a patient a poisonous external application instead of a mixture, or gives two tablespoonfuls of some active medicine instead of a teaspoonful - these we believe to be easily preventible. The first step should be taken in the druggist's establishment. He might fairly be required to keep all poisonous matters in vessels of some peculiar construction.

But here occurs the question-How shall we decide on what are to be considered poisonous matters? The wrant of a satisfactory answer to this question led some of those who have attempted to legislate on the subject into some absurdities They made an arbitrary selection of several articles which were well known to be poisonous, and directed these to be secluded in a "poison closet," leaving others perfectly free which were just as dangerous. They omitted to lay down any rule which could serve as a guide in deciding what ought and what ought not to be considered a poison. Now we believe it is perfectly easy to give such a definition as might serve for the basis of legislation--a definition which shall include all known substances, and any others which may be hereafter discovered and introduced into medicine. It is clear that such a definition can only be based on the dose. 'The line between danger and safety is sometimes very narrow, and doctors themselves differ about poisonous doses; but we believe we shall lay down a rule capable of universal application when we say that every liquid should be considered as poisonous the maximum dose of which for ordinary therapeutical purposes does not exceed one drachm, and every solid substance the maximum dose of which does not exceed five grains. All such liquids and solids vendors should keep in such vessels as would indicate the dangerous nature of their contents, and this, we believe, would effectually guard against one class of accidents. It is just as easy to provide against the others. Most external applications are dangerous if swallowed, and consequently these should be placed in bottles of a distinctive shape, which wonld prevent their being mistaken for medicines to be taken internally.

There is but one other source of danger to be guarded against, and that is, the possible administration of an overdose of some powerful medicine. This might be easily prevented by the use in such cases of bottles of the same peculiar construction as those in which it is proposed to keep poisons on the druggists' shelves; and we are of opinion that the bottles with contracted necks are well suited for both purposes, affording, as they are acknowledged to do, sufficient indication to dispenser, nurse, or patient, of the potent nature of the medicine.

If these precantions were adopted, in our opinion accidents could only happen from ignorance or criminal carelessness, for which individuals may be fairly made responsible; and there can be no doubt that a system founded on the principles we have laid down would most effectually prevent a class of poisonings which are unhappily too often a scandal to medical men and druggists, and a source of grief to their patients and customers.

We have not touched upon the question how chemists and apothecaries are to be brought to adopt the scheme proposed whether it should be by Act of Parliament or otberwise; but we are strongly inclined to the belief that a simple recommendation emanating from either the Home Office or the Poyal College of Physicians would be sufficient. The best and most respectable portion of the fraternity would immediately act upon it, and the rest wonld ultimately follow their example. A system of safeguards so recommended in the public behalf would unquestionably be insisted upon by the physic-taking public; and when once become an establiched custom, any neglect of or departure from its provisions would imply such an utter want of ordinary care and prudence as to be altogether without excuse and deserving the severest punishment.

In conclusion, perhaps you will allow us to make known to those parties who, in consequence of the allusion you were pleased to make to our newly-invented bottles, have addressed to us letters of inquiry on the subject, that, apart from the public advantage which we firmly believe would fullow the general use of these vessels, we have no interest whatever in the matter. Anyone may get information, and purchase the botiles upon exactly the same terms as ourselves, by applying to Mr. Toogood, 37, Mount-street, or to Messrs. Mlaw, Aldersgate-street. To those who may entertain doubts as to the practicability of the plan we have proposed, we may say that it may be seen here in full operation, and we shall be pleased to receive a visit from all who may wish to satisfy themselves upon that point.

We are, Sir, your rnost obedient servants,

New Bond-strect, Aug. 7ti, 1860. SAVORY \& MoORE.

\section{ON PERIODICITY AS A CEARACTER OF DISEASE.}

(NOTE FROM DR. TILT.)

To the Liditor of THE LANOET.

Sir,- - I should feel obliged if you would allow me to add a Sew lines in confirmation of the views expressed by Mr. Huches in his paper on the above subject, which appeared in Try LAxcxe of the 4 th inst. Believing that the periodical phenomena occurring in the system are to be referred to the ganglionic nerves, and that each menstrual process is analogons to a fit of ague, I was induced, many years ago, to try the best toner of the vaso-motor nerves-sulpbate of quinine, whenever the mensirual period recurred every second or third week instead of at the normal period, the fourth week. I have very seldom found the plan to fail, unless the change in the menstrual type was causel by severe inflammation of the neck of the womb. I have given the sulphate of quinine alone, in doses of from two to three grains every night or every other night, immediately after the subsidence of menstruation. The same dose of sulphate of quinine may be combined with two grains of extract of hyoscyamus, or a quarter of a grain of extract of opium, when nervous symptoms predominate, or with sulphate of iron if the patient be anæmic, or with extract of aloes in sufficient quantities to prevent constipation.

For more ample details I may refer Mr. Hughes to a paper which you did me the honour to publish in 1851, and to a chapter in my work on Diseases of Women, "On Type in Menstruation."

I remain, Sir, faithfully yours,

Grosvenor-street, August 8th, 1860 . E. T. TruT, M.D.

\section{COLLEGE OF PHYSICIANS, EDINBURGH.} To the Editor of Trie LAXCET.

SIR, - As it has been said that nearly all the gentlemen who have availed themselves of the year of grace to enter the Royal College of Physicians, Edinburgh, were in possession of one qualification only, and that, in the majority of instances, it was the licence of the Society of Apothecaries, I have taken the names from the columns of THE LA TCET, as they have appeared in it, and from the list which the Cullege published to Christmas, and I find that the total number is 862. Of this number, 344 have the double qualification, 348 belong to a College of Surgeons only; whilst there are only 103 with the single medical qualification, chicfly the licence of the Apothecaries' Society, London, a few M.D.s, and two or three gentlemen from Ireland: 117 names are not in this year's Pegister; whilst 64 of the gentlemen are Feliows of the College of Surgeons, England, and 66 are M.D.s of different universities.

The gentlemen who have availed themselves of the privilege nust have thonght well of the qualification, notwithstanding the unwise attempt which has been made to cry it down by 